\title{
O corpo humano no cotidiano: analogias como recurso no ensino morfofuncional
}

\author{
The human body in everyday life: analogies as a morphofunctional teaching resource
}

El cuerpo humano en lo cotidiano: analogías como recurso en la enseñanza morfofuncional

Tassio Danilo Rego de Queiroz ${ }^{1 *}$, Sabrina Mércia dos Santos Siebra ${ }^{1}$, José Edvan de Souza Júnior ${ }^{1}$, Ellany Gurgel Cosme do Nascimento ${ }^{1}$, Allyssandra Maria Lima Rodrigues Maia ${ }^{1}$, Cleanto Rogério Rego Fernandes².

\section{RESUMO}

Objetivo: Relatar a experiência na utilização de analogias por monitores como metodologia ativa de ensino e aprendizagem dos componentes curriculares morfofisiológicos do curso de medicina. Relato de experiência: Cinco analogias foram desenvolvidas comparando objetos do dia a dia com as seguintes estruturas do corpo humano: miocárdio, capilares sinusoidais, células ciliares do epitélio respiratório, melanócitos epidérmicos e células ganglionares da retina. A atividade consistiu em comparar as semelhanças estruturais e funcionais de diferentes regiões do corpo humano com sua contraparte cotidiana, bem como evidenciar as suas diferenças, com o auxílio de imagens sem descrição mostradas aos alunos. O trabalho foi realizado nas aulas de laboratório por monitores de Histologia com sessenta alunos do primeiro e segundo semestres do curso de Medicina. Considerações finais: As analogias foram desenvolvidas e aplicadas com sucesso, as discussões foram além do objetivo inicial em algumas situações, sendo discutida, em todos os casos, a limitação da analogia, evitando o desenvolvimento de equívocos. As analogias são ferramentas úteis para o ensino e aprendizagem das ciências morfológicas, o que requer mais estudos para testar seu uso e eficácia.

Palavras-chave: Histologia, Ilustração médica, Aprendizagem por associação.

\begin{abstract}
Objective: Report the experience of use of analogies by undergraduate teaching assistants as an active methodology for teaching and learning of morphophysiological curricular components of the medical course. Experience report: Five analogies were developed by comparing everyday objects with the following human body structures: myocardium, sinusoidal capillaries, ciliary cells of the respiratory epithelium, epidermal melanocytes, and retinal ganglion cells. The activity consisted in comparing the structural and functional similarities of several human body regions and its everyday counterpart, as well as highlighting its differences, with the help of images without description which were shown to the students. The work was performed in the laboratory classes by teaching undergraduate assistants of histology with sixty first- and second-term medical students. Final considerations: The analogies were successfully developed and applied, the discussions were beyond the initial objective in some situations, being discussed, in all cases, the limitation of the analogy, avoiding the development of misconceptions. Analogies are helpful tools for teaching and learning morphological sciences, which requires further studies to test their use and efficacy.
\end{abstract}

Keywords: Histology, Medical illustration, Association learning.

\section{RESUMEN}

Objetivo: Informar la experiencia en el uso de analogías por parte de monitores como metodología activa de enseñanza y aprendizaje de los componentes morfofisiológicos curriculares de la carrera de medicina. Informe de experiencia: Se desarrollaron cinco analogías comparando objetos cotidianos con las siguientes estructuras del cuerpo humano: miocardio, capilares sinusoidales, células ciliadas del epitelio respiratorio, melanocitos epidérmicos y células ganglionares de la retina. La actividad consistió en comparar las similitudes estructurales y funcionales de diferentes regiones del cuerpo humano con su contraparte diaria, así como resaltar sus diferencias, con la ayuda de imágenes sin descripción mostradas a los estudiantes. El trabajo fue realizado en las clases de laboratorio por monitores de Histología con sesenta alumnos del primer y segundo semestre de la

${ }^{1}$ Universidade do Estado do Rio Grande do Norte (UERN), Mossoró - RN.

*E-mail: tassioqueiroz@alu.uern.br

${ }^{2}$ Instituto Federal de Educação, Ciência e Tecnologia do Ceará (IFCE), Acopiara - CE.

SUBMETIDO EM: 8/2021

ACEITO EM: 9/2021

PUBLICADO EM: 9/2021 
carrera de Medicina. Consideraciones finales: Las analogías se desarrollaron y aplicaron con éxito, las discusiones fueron más allá del objetivo inicial en algunas situaciones, discutiendo, en todos los casos, la limitación de la analogía, evitando el desarrollo de errores. Las analogías son herramientas útiles para la enseñanza y el aprendizaje de las ciencias morfológicas, lo que requiere más estudios para probar su uso y efectividad.

Palabras clave: Histología, Ilustración médica, Aprendizaje por asociación.

\section{INTRODUÇÃO}

$\mathrm{Na}$ educação médica contemporânea, destaca-se a incorporação das metodologias ativas de ensinoaprendizagem e estruturas curriculares que aproximem os conhecimentos dos ciclos básico e aplicado para além da teoria, consoante às Diretrizes Curriculares Nacionais (DCNs) do Curso de Graduação em Medicina (FRANCO CAGS, et al., 2014).

A monitoria consiste em um espaço formativo no ensino superior, tanto para o monitor quanto para o docente orientador, que otimiza 0 ganho de saberes e age de forma complementar às preconizações educativas recentes, também implementando metodologias de ensino-aprendizagem, com a possibilidade de motivar os estudantes universitários (DANTAS OM, 2014; JÚNIOR EA, et al., 2019)

Em inúmeras situações, o aprendizado no ensino morfológico caracteriza-se mecânico e laborioso, sendo visto com empecilhos e desmotivação, frente à visão memorizadora de estruturas e nomenclaturas difíceis, o que rememora o processo de educação bancária, mecanicista e depositadora de conhecimentos (GIROUX HA, 2020). A provocação via novos instrumentos de ensino é uma alternativa importante, inclusive nas ciências morfofuncionais (MATTOS MP, 2017).

No contexto do ensino, em particular da educação médica, o uso de analogias tem sido amplamente empregado. A comparação entre estruturas do organismo humano e produtos do cotidiano já conhecidos pela população em geral favorece um primeiro entendimento da estrutura a ser estudada ou a compreensão de um aspecto em particular que costuma ser de difícil entendimento. Isso ocorre quando a estrutura biológica e o produto cotidiano comparados apresentam semelhança estrutural e funcional. Nessa linha, existe, por exemplo, a analogia entre um sistema de baterias e os a eletrocardiografia (LUJAN HL, et al., 2020).

A estratégia metodológica do uso de analogias como ferramenta de ensino fundamenta-se na necessidade educativa de ampliação dos recursos didáticos criativos e eficientes para o repasse informacional dentro da universidade (SILVA JF, 2018). A utilização analógica, em consideração à aprendizagem muitas vezes abstrata de Ciências e a construção permanente de novas abordagens, ganha destaque em razão de otimizar a compreensão de conceitos científicos tomando como partida a comparação das semelhanças destes com objetos comparados já conhecidos pelos estudantes (MARTINS D, et al., 2020).

O presente trabalho justifica-se pela abordagem criativa no aprendizado da histologia humana, o que diversifica o repertório de possibilidades para o aprender em microscopia, caracterizando-se inovadora a associação simultânea morfológica e funcional feita no que tange à incorporação do cotidiano no estudo de estruturas do corpo. Assim, o artigo relata a experiência na monitoria de Histologia quanto à utilização de analogias no ensino morfofuncional microscópico, desenvolvidas a partir das vivências nas atividades de ensino, correlacionando com elementos do dia-a-dia dos universitários.

\section{RELATO DE EXPERIÊNCIA}

Trata-se de um estudo descritivo, do tipo relato de experiência, produzido frente às vivências dos monitores da UERN, especificamente no intervalo de outubro de 2019 até meados de março de 2020 na disciplina de Histologia, ofertada nos componentes curriculares obrigatórios de Módulo Morfofuncional I e II, no primeiro e segundo semestres, respectivamente, do curso de graduação de Medicina da UERN, em Mossoró. O público-alvo foi constituído por 60 alunos, correspondente à totalidade de alunos matriculados na disciplina. 
No presente trabalho, foram desenvolvidas cinco analogias para elucidar algumas estruturas biológicas através da comparação com objetos ou situações do cotidiano. As atividades ocorreram durante o semestre acadêmico. A aplicação das tabelas analógicas objetiva aproximar o raciocínio do funcionamento de estruturas corporais com a realidade cotidiana, de forma a se perceber que uma mesma funcionalidade prática coexiste no corpo humano e em objetos ou situações habituais.

Para a elaboração das analogias, foram utilizadas fotografias registradas pelos próprios autores e ilustrações elaboradas a partir de componentes do Servier Medical Art ${ }^{\circledR}$, disponíveis para livre uso de edição e compartilhamento sob a licença Creative Commons, e do Microsoft Office Power Point $365 \AA$.

\section{Analogia entre contração miocárdica e torcer a roupa para secar}

A contração miocárdica propele o sangue adiante ao diminuir o volume das câmaras gerando consequente aumento pressórico, dinâmica primordial em aumentar a eficiência do débito cardíaco sistólico pelo arranjo das fibras musculares em orientação oblíqua que, quando contraídas, promovem um padrão torsional de compressão do ápice para a base (BLOECHLINGER S, et al., 2012; BUCKBERG GD, et al., 2018; VASUDEVAN V, et al., 2019). Essa geometria e sua função hemodinâmica podem ser difíceis de visualização. Sendo válida uma comparação com o ato de torcer a roupa para secá-la após sua lavagem, pois a torção é bem mais eficiente para eliminar água do que simplesmente espremê-la concentricamente (Figura 1). Tanto no bombeamento muscular cardíaco quanto na distensão torcional do item lavado, ocorre menos dispêndio de força para a realização do mesmo trabalho, configurando vantagem mecânica.

Figura 1 - Analogia entre o padrão torsional de contração miocárdica do ápice à base ( $\mathrm{A}$ e $\mathrm{B})$ e a torção da roupa molhada $(\mathrm{C})$, com as setas sinalizadoras do movimento realizado em comum em ambas as situações.
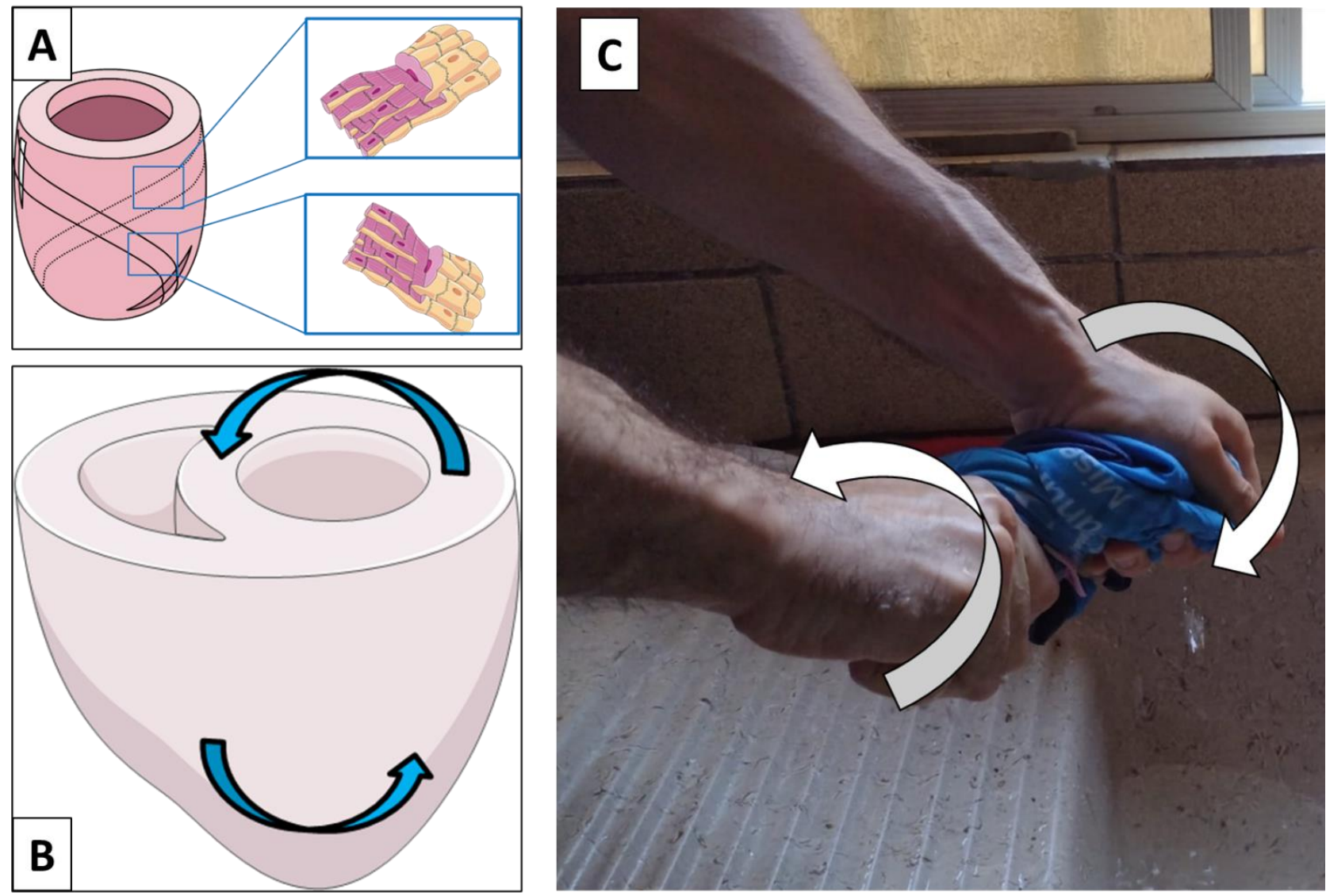

Nota: $(A)$ e (B) Ilustrações construídas no Microsoft Office Power Point 365 §, elaboradas pelos autores a partir de componentes básicos do Servier Medical Art ® disponíveis para livre uso de edição e compartilhamento sob a licença Creative Commons (CC BY 3.0). (C) Fotografia registrada pelos próprios autores, editada no Microsoft Office Power Point 365 ß. 2021.

Fonte: Queiroz TDR, et al., 2021. Baseado em Bloechlinger S, et al., 2012; Buckberg GD, et al., 2018; Vasudevan V, et al., 2019. 


\section{Analogia entre o sistema microvascular hepático e as curvas no autódromo de Fórmula 1}

A elevada especialização do sistema microvascular hepático para regular a distribuição do fluxo sanguíneo constitui-se de vasos estreitos, tortuosos e anastomosados, principalmente os sinusóides periportais, promovendo avantajada oposição ao fluxo sanguíneo (OLIVARES RAU, 2018). Esse trajeto é importante na medida em que, com a lentificação do fluxo, o sangue permanece mais tempo, logo, a atuação do sistema reticuloendotelial e a detoxificação metabólica hepática tornam-se mais eficientes (KIERSZENBAUM AL, 2020).

Analogamente, as curvas presentes no autódromo de Fórmula 1, com seus meandros na pista e o maior afunilamento espacial para trafegar, exigem a diminuição de velocidade, para não ocorrer a "saída pela tangente" (Figura 2). Após o acidente vitimador do piloto Ayrton Senna, algumas curvas foram adicionadas ao autódromo de Ímola (Itália). De fato, nenhum piloto morreu em uma corrida oficial da categoria após essa mudança (CHAGAS CCM, 2014). A transformação do trecho em forma de "S" assemelha-se aos sinusóides hepáticos, compartilhando-se a estrutura morfológica meândrica e a desaceleração do material que flui - 0 sangue pelos microvasos sanguíneos do fígado e os veículos no pavimento esportivo.

Figura 2 - Analogia entre o padrão sinusoidal dos capilares hepáticos (indicado pela seta em A) e o trecho perigoso do autódromo de Ímola, na Itália, com a adição de uma curva no pavimento esportivo (destacada em B).

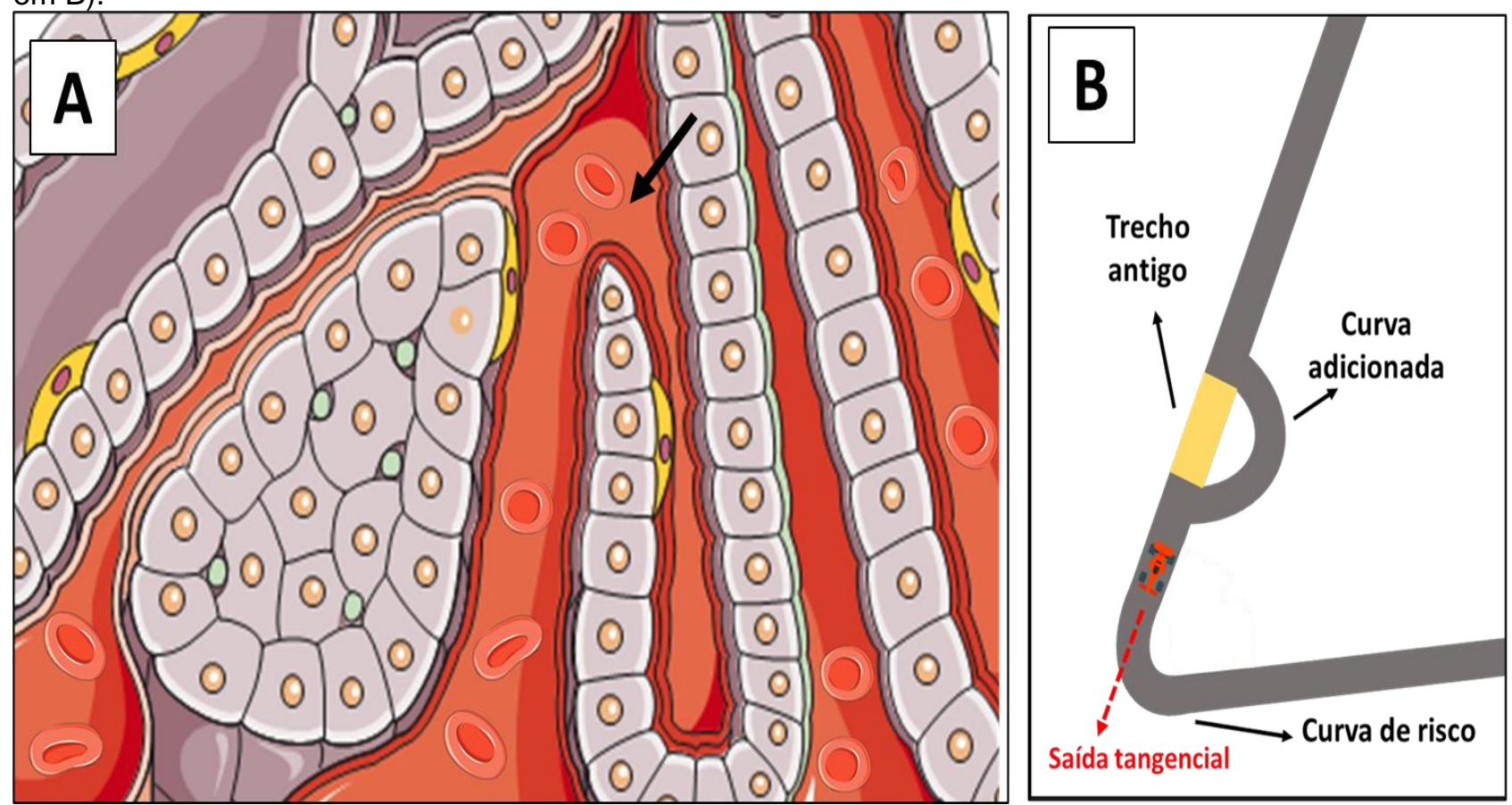

Nota: (A) llustração construída no Microsoft Office Power Point $365 \AA$, elaborada pelos autores a partir de componentes básicos do Servier Medical Art $\AA^{\circledR}$ disponíveis para livre uso de edição e compartilhamento sob a licença Creative Commons (CC BY 3.0). (B) llustração elaborada pelos autores a partir do Microsoft Office Power Point 365 @. 2021.

Fonte: Queiroz TDR, et al., 2021. Baseado em Chagas CCM, 2014; Zapotoczny B, et al., 2017; Olivares RAU, 2018.

\section{Analogia entre as células ciliadas do sistema respiratório e as cerdas da escova dental}

A mucosa das vias aéreas é formada pelo epitélio pseudo-estratificado cilíndrico com cílios e células caliciformes composto por cinco principais células: ciliadas, células em escova, células de pequenos grânulos (Kulchitsky), caliciformes e basais. Predominam as células ciliadas, cuja dinâmica é fundamental para a translocação mucociliar (GUAN W, et al., 2018). Alguns aspectos dos cílios afetam sua função, como número e comprimento dos cílios, organização do batimento, frequência e amplitude do movimento (VARAS SM, et al., 2019). 
Similarmente, para a realização da limpeza oral, é essencial a integridade das cerdas da escova dentária. O tempo de utilização das cerdas por três meses demonstra ser crítico para o dano estrutural (TENÓRIO EP, et al., 2018). Em razão do desgaste, a altura das cerdas é reduzida, e perde-se sua organização regular, enfileirada e vertical (Figura 3). Essa alteração assemelha-se à pavimentação epitelial metaplásica da via aérea superior frente a indutores de estresse e adaptação celular, como o tabagismo (FERMAN-CANO F, et al., 2018). As mudanças estruturais no epitélio respiratório evidenciam a necessidade de um tecido superficial sadio para limpar o trato respiratório, tal qual a escova íntegra limpa eficazmente a cavidade oral.

Figura 3 - Analogia entre a altura do epitélio respiratório traqueal saudável (A) e sua pavimentação metaplásica (B) e o desgaste vertical das cerdas da escova dentária antes nova e enfileirada (C) e depois usada e mais horizontal após desgaste temporal (D).
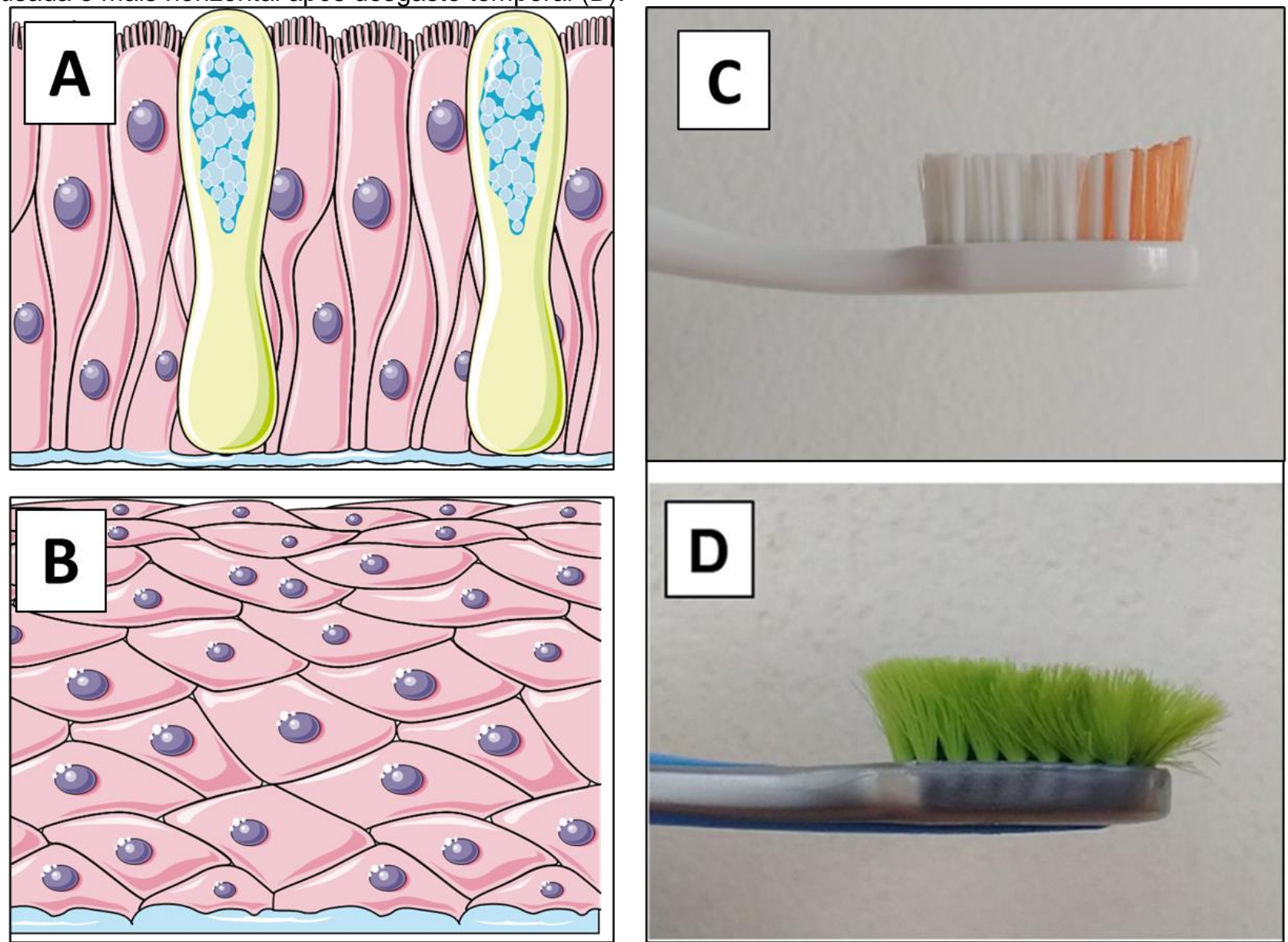

Nota: (A) e (B) Ilustrações construídas no Microsoft Office Power Point 365 §, elaboradas pelos autores a partir de componentes do Servier Medical Art ${ }^{\circledR}$ disponíveis para livre uso de edição e compartilhamento sob a licença Creative Commons (CC BY 3.0). (C) e (D) Fotografias registradas pelos próprios autores, editadas no Microsoft Office Power Point $365 \AA 2021$.

Fonte: Queiroz TDR, et al., 2021. Baseado em Guan W, et al., 2018; Tenório EP, et al., 2018; Ferman-Cano F, et al., 2018.

\section{Analogia entre os melanócitos epidérmicos e o guarda-sol utilizado pelas pessoas}

Os melanócitos localizam-se no estrato basal do epitélio estratificado pavimentoso queratinizado da pele e emitem projeções citoplasmáticas para levar o pigmento melânico produzido por eles até os queratinócitos, os quais ficam nas camadas mais superficiais da epiderme e são desprovidos, por si só, de defesas contra a radiação solar (CORREIA MS, et al., 2018). Nos queratinócitos, a localização da melanina é principalmente supranuclear, protegendo o material genético presente no núcleo contra essa radiação (MOREIRAS H, et al., 2021; UPADHYAY PR, et al., 2021). 
O efeito de capuz pigmentar assemelha-se ao uso de guarda-sol pelas pessoas para se protegerem da radiação solar em praias e em deslocamentos diários nos ambientes externos ensolarados (Figura 4). Tal intersecção encontra significância não apenas pela mesma radiação incidente em comum, mas pelo posicionamento espacial de ambas as estruturas para cumprir o papel de otimização protetiva aos efeitos deletérios da exposição ao Sol.

Figura 4 - Analogia entre a proteção supranuclear feita pelo pigmento melânico nos queratinócitos superficiais da pele $(A)$ e o efeito anteparo do guarda-sol na praia como proteção à radiação ultravioleta solar(B).
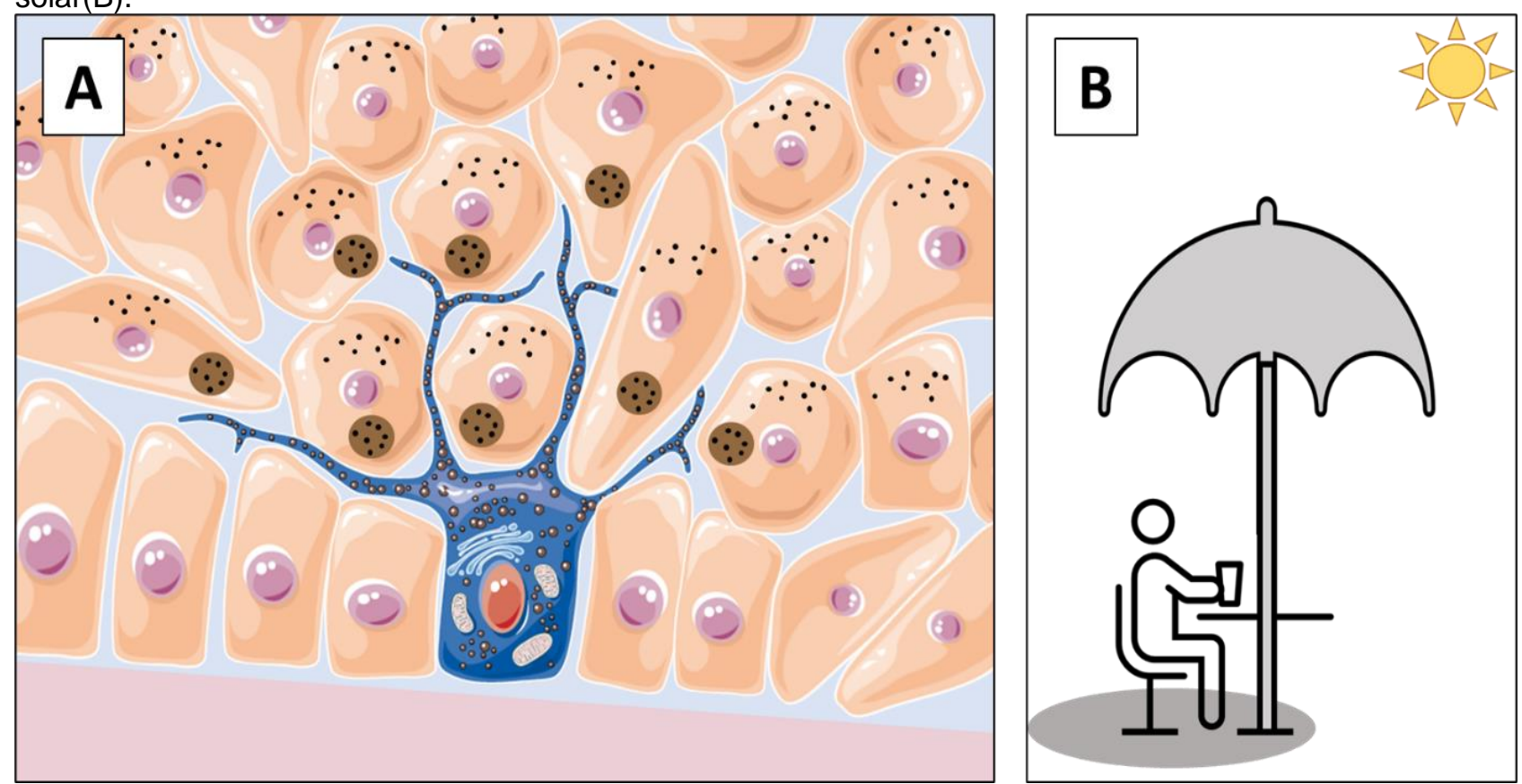

Nota: (A) Ilustração construída no Microsoft Office Power Point 365 ®, elaborada pelos autores a partir de componentes básicos do Servier Medical Art $\AA^{\circledR}$ disponíveis para livre uso de edição e compartilhamento sob a licença Creative Commons (CC BY 3.0). (B) Ilustração elaborada pelos autores a partir do Microsoft Office Power Point 365 ®. 2021.

Fonte: Queiroz TDR, et al., 2021. Baseado em Correia MS, et al., 2018; Moreiras H, et al., 2021; Upadhyay PR, et al., 2021.

\section{Analogia entre as células ganglionares da retina e o sensor do poste de iluminação pública}

Os receptores sensoriais de luz da retina não se limitam a projetar para o encéfalo a informação para a percepção visual, pois também se projetam diretamente para o núcleo supraquiasmático (NSQ) do hipotálamo anterior, informando sobre a luminosidade ambiental. O NSQ gera uma oscilação endógena que origina os ritmos circadianos (sono-vigília), sendo necessária sua sincronização aos ciclos externos (claroescuro). Dessa forma, a retina atua como um sensor de luminosidade ambiental, ajustando o "relógio biológico" ao ciclo claro-escuro ambiental (REFINETTI R, 2016). Os cones e os bastonetes não são as únicas células retinianas capazes de realizar fototransdução. Através da expressão do pigmento melanopsina, as células ganglionares são diretamente estimuladas pela luz, sendo estrategicamente localizadas na camada mais superficial da retina. Uma parcela dos axônios ganglionares projeta-se, inclusive, diretamente para o NSQ (SANES JR e MASLAND RH, 2015).

Em semelhança, os postes de iluminação pública possuem um sensor que detecta a ausência/presença da radiação solar, sinaliza para o desligamento da lâmpada quando dia e o ligamento durante a noite (Figura 5). Esse sensor não responde apenas à luz natural, mas também a outros tipos de feixes incidentes, o que motivou a inserção lúdica da imagem de uma criança brincando com um laser e incidindo um feixe de luz artificial no sensor, apagando a lâmpada, mesmo à noite. Portanto, o olho, para além de uma "câmera" importante à percepção visual, é um sensor de luz para ajustar o nosso "relógio biológico". 
Figura 5 - Analogia entre a posição superficial e a função sinalizadora das células ganglionares retinianas (A) e o sensor de luz nos postes de iluminação pública (B).

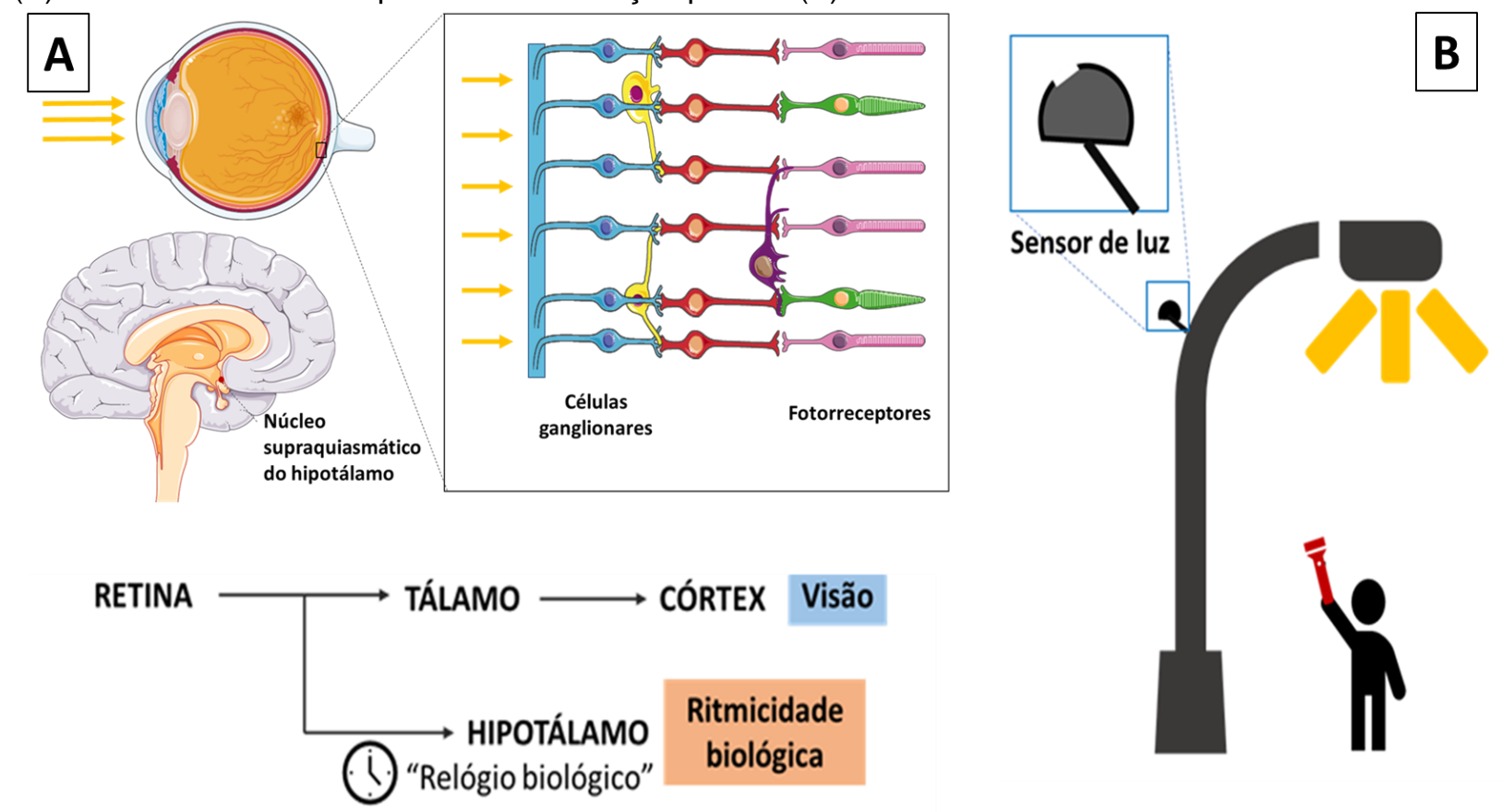

Nota: (A) llustração construída no Microsoft Office Power Point $365 \AA$, elaborada pelos autores a partir de componentes básicos do Servier Medical Art ® disponíveis para livre uso de edição e compartilhamento sob a licença Creative Commons (CC BY 3.0). (B) Ilustração elaborada pelos autores a partir do Microsoft Office Power Point 365 B. 2021.

Fonte: Queiroz TDR, et al., 2021. Baseado em Refinetti R, 2016; Sanes JR e Masland RH, 2015; Lou L, et al., 2021.

\section{Impressões, desafios e considerações sobre a experiência das analogias}

Os discentes eram estimulados a formar conexões entre os conhecimentos cotidianos e histológicos mediante a exposição das imagens comparativas no início das monitorias sobre os tecidos específicos e a proposição de realizarem "chuva de ideias" sobre o tema a partir das representações não verbais, com a construção do raciocínio interseccional por todos da turma. Isso viabilizou a participação ativa dos estudantes, para além da exposição linear do assunto pelos monitores.

A partir da abordagem analógica, os autores captaram inúmeros pontos positivos da experiência para os alunos da turma, monitores e docentes da disciplina. Os diversos questionamentos realizados pelos alunos ao longo dos encontros contemplaram de forma interdisciplinar diversas áreas do conhecimento. Em especial a biologia evolutiva dos organismos e os mecanismos adaptativos, a importância da construção da autonomia do pensamento crítico, da curiosidade e do conhecimento criativo na universidade.

Ainda, foi possível evidenciar a necessidade de desenvolvimento da habilidade de falar em público, a partir dos momentos em sala de aula, habilidade bastante requisitada nas metodologias ativas, no exercício da própria monitoria e na didática ofertada pelos professores na academia.

Todavia, notou-se nos alunos um pouco de hesitação diante da nova abordagem em ensino, acompanhada também da curiosidade discente, o que é esperado frente a novas abordagens de ensino que desconstroem a perspectiva de repasse tradicional do conhecimento.

Constituíram sérios desafios observados pelos autores na disciplina de histologia: cobranças excessivas de nomenclaturas estruturais e identificação da técnica de coloração da lâmina, aulas expositivas assentadas em slides textuais e visuais com decorativismo de marcações. Esse cenário tende a inibir participações expressivas de novos modelos didáticos, os quais podem ser elaborados não somente por docentes, mas também pelos alunos e monitores, tal qual demonstra o presente trabalho. 


\section{DISCUSSÃO}

As analogias configuram-se materiais interessantes no estímulo ao aprendizado dos alunos e no ganho de resultados, facilitando o desenvolvimento de significância conceitual, sobretudo em áreas complexas do currículo (PAMIDI N, 2020; TAYLOR C et al, 2018). O uso de analogias também traz a perspectiva de uma educação autônoma enquanto recurso que aproxima, de forma dialógica, saberes aparentemente dissociados e fomenta questionamentos dos indivíduos frente à teoria microscópica posta (BRIGHENTE MF e MESQUIDA P, 2016).

A experiência prática na identificação de analogias apropriadas para conceitos biológicos incentiva o desenvolvimento das habilidades de pensamento dos alunos. Esperam-se, ao invés de repetições e memorizações de termos, a aplicabilidade e análise dos alunos, pois as analogias focalizam os conceitos maiores que se tentam ensinar, em detrimento de detalhes biológicos, e, ainda, trazem consigo um aspecto lúdico em sala de aula (GARDNER RD, 2016).

Todavia, o uso de analogias deve ser baseado em forte arcabouço teórico e evidências científicas. É preciso atenção a possíveis limitações, pois o objeto ou fenômeno conhecido não é idêntico à sua contraparte a ser conhecida e sua utilização inadequada pode levar a concepções equivocadas (HAGLUND $\mathrm{J}$ e JEPPSSON F, 2012). Assim, por exemplo, ao se fazer alusão entre o olho e o funcionamento das máquinas fotográficas, é preciso pôr em relevo a necessidade de explicar e limitar a comparação feita, demonstrando suas semelhanças e destacando suas diferenças, pois o olho humano não é idêntico a uma câmera, mas sim compartilha algumas características enquanto mecanismo óptico (PEREIRA RF e NEVES MCD, 2011).

$\mathrm{Na}$ abordagem específica sobre o ritmo sono-vigília e a microscopia retiniana, a analogia proporcionou, para além do objetivo inicial, uma reflexão sobre a relação da sociedade contemporânea com as tecnologias e suas consequências para os ritmos biológicos. É importante destacar as perturbações no ritmo circadiano e o prejuízo à qualidade do sono das pessoas em decorrência do desenvolvimento da luz artificial por energia elétrica e seu uso doméstico. Mais recentemente, esses transtornos têm sido ampliados pela exposição a telas de celulares e computadores (ROD NH, et al., 2019).

Já foi observada, inclusive, a má qualidade do sono de estudantes universitários do curso médico (CORRÊA CC, et al., 2017). Essa analogia foi incluída no trabalho, juntamente com uma discussão sobre a higiene do sono, dada sua relevância para a saúde e desenvolvimento acadêmico dos estudantes, uma vez que o sono é fundamental para a saúde e indispensável para o aprendizado (LANDMANN N, et al., 2014).

A experiência metodológica com as analogias configurou-se produtiva para os monitores, docentes e estudantes da disciplina, empreendendo novos horizontes na aplicação de possibilidades de ensinoaprendizagem na área morfológica. Despertou-se a importância dos elementos criatividade, curiosidade, interdisciplinaridade e autonomia do pensamento crítico dentro da esfera universitária, o que ainda é desafiador frente ao tradicionalismo acadêmico. Assim, o aprendizado na histologia torna-se atrativo, menos automático, desperta a motivação dos alunos para a aquisição dos conhecimentos e possibilita conexões do saber acadêmico com situações cotidianas. Em estudos posteriores, o uso de analogias na educação médica deve ser ampliado e, em particular, ter sua aceitabilidade e eficácia avaliadas.

\section{REFERÊNCIAS}

1. BLOECHLINGER S, et al. Left ventricular rotation: a neglected aspect of the cardiac cycle. In: PINSKY M, et al., editors. Applied physiology in intensive care medicine 1. Berlin: Springer; 2012; 103-10p.

2. BRIGHENTE MF, MESQUIDA P. Paulo Freire: da denúncia da educação bancária ao anúncio de uma pedagogia libertadora. Pro-Posições, 2016; 27(1): 155-177.

3. BUCKBERG GD, et al. What is the heart? Anatomy, function, pathophysiology, and misconceptions. Journal of cardiovascular development and disease, 2018; 5(2): 33.

4. CHAGAS CCM. A Física no ensino médio através do estudo de fenômenos físicos em um automóvel, CE. Dissertação (Mestrado em Ensino de Ciências e Matemática) - Centro de Ciências. Universidade Federal do Ceará, Fortaleza, 2014; 229p. 
5. CORRÊA CC, et al. Qualidade de sono em estudantes de medicina: comparação das diferentes fases do curso. Jornal Brasileiro de Pneumologia, 2017; 43(4): 285-289.

6. CORREIA MS, et al. Melanin transferred to keratinocytes resides in nondegradative endocytic compartments. J Invest Dermatol. 2018; 138(3): 637-46.

7. DANTAS OM. Monitoria: fonte de saberes à docência superior. Revista Brasileira de Estudos Pedagógicos, 2014; 95: 567-589.

8. FERMAN-CANO F, et al. Metaplasia de vías aéreas asociada a tabaquismo y contaminación ambiental mediante esputo. Rev Med Inst Mex Seguro Soc., 2018; 56(1): 46-52.

9. FRANCO CAGS, et al. The medicine curriculum and competences croposed for curriculum cuidelines. Rev Bras Educ Médica, 2014; 38(2): 221-30.

10. GARDNER RD. Teaching biology with extended analogies. The American Biology Teacher, 2016; 6: 512-514.

11. GIROUX HA. On critical pedagogy. 2nd ed. London: Bloomsbury Academic; 2020; 280p.

12. GUAN W, et al. Motile ciliary disorders in chronic airway inflammatory diseases: critical target for interventions. Curr Allergy Asthma Rep., 2018; 18(9): 48.

13. HAGLUND J, JEPPSSON F. Using self-generated analogies in teaching of thermodynamics. Journal of Research in Science Teaching, 2012; 49(7): 898-921.

14. KIERSZENBAUM AL. Histología y biología celular: introducción a la anatomía patológica. 5a ed. Elsevier Health Sciences, 2020; 824p.

15. JÚNIOR EA, et al. O uso de metodologias ativas na prática de monitoria acadêmica no curso de medicina: aprendizado baseado em problemas/The use of active methodologies in academic monitoring practice in medicine course: learning based on problems. Brazilian Journal of Development, 2019; 5(11): 26281-26285.

16. LANDMANN N, et al. The reorganisation of memory during sleep. Sleep medicine reviews, 2014; 18(6): 531-41.

17. LOU L, et al. Long-Term Narrowband Lighting Influences Activity but Not Intrinsically Photosensitive Retinal Ganglion Cell-Driven Pupil Responses. Frontiers in Physiology, 2021; 12: 711525.

18. LUJAN HL, et al. Electrify your class with a simple battery: battery demonstration of electrocardiogram vectors. Adv Physiol Educ., 2020; 44: 394-9.

19. MARTINS D, et al. O Papel dos Modelos Computacionais e das Analogias na Aprendizagem do Processo de Interação Fármaco-Enzima no Ensino Fundamentado em Modelagem. Revista Brasileira de Pesquisa em Educação em Ciências, 2020; 823-854.

20. MATTOS MP. Metodologias ativas auxiliando no aprendizado das ciências morfofuncionais numa perspectiva clínica: um relato de experiência. Rev Ciências Médicas e Biológicas, 2017; 16(2): 146.

21. MOREIRAS $\mathrm{H}$, et al. Melanin Transfer in the Epidermis: The Pursuit of Skin Pigmentation Control Mechanisms. International Journal of Molecular Sciences, 2021; 22(9): 4466.

22. OLIVARES RAU. Fisiopatología. La ciencia del porqué y el cómo. Elsevier Health Sciences, 2018; 824p.

23. PAMIDI $N$. Use of essential analogies in clinical anatomy active learning curriculum: $A$ personal reflection. Translational Research in Anatomy, 2020; 18: 100062.

24. PEREIRA RF, NEVES MCD. Adaptando uma câmera fotográfica manual simples para fotografar o céu. Astronomia e Cosmologia: fatos, conjecturas e refutações. 1rMaringá: Eduem, 2011;249p.

25. REFINETTI R. Circadian physiology. 3rd ed. Taylor \& Francis; 2016; 749p.

26. ROD NH, et al. Overnight smartphone use: a new public health challenge? A novel study design based on highresolution smartphone data. PLoS One, 2019; 13(10): 1-12.

27. SANES JR, MASLAND RH. The types of retinal ganglion cells: current status and implications for neuronal classification. Annual Review of Neuroscience, 2015; 38: 221-46.

28. SILVA JF. Didática no Ensino Superior: estratégias de ensino adequadas à arte de ensinar. Educação Por Escrito, 2018; 9 (2): 204-219.

29. TAYLOR C, DEWSBURY BM. On the problem and promise of metaphor use in science and science communication. Journal of microbiology \& biology education, 2018; 19(1): 19-1.

30. TENÓRIO EP, et al. Impacto do tempo médio de uso da escova dental sobre o nível de desgaste das cerdas e a condição periodontal em adultos. Revista da AcBO, 2018; 7(2): 153-60.

31. UPADHYAY PR, et al. Participation of Keratinocyte-and Fibroblast-derived factors in melanocyte homeostasis, the response to UV, and pigmentary disorders. Pigment Cell \& Melanoma Research, 2021; 34(4): 762-776.

32. VARAS SM, et al. Transportadores de iones en pulmón: uso como dianas terapéuticas. Revista Medicina, 2019; 79(4): 303-14.

33. VASUDEVAN V, et al. Torsional motion of the left ventricle does not affect ventricular fluid dynamics of both foetal and adult hearts. Journal of biomechanics, 2019; 96: 109357.

34. ZAPOTOCZNY B, et al. Quantification of fenestrations in liver sinusoidal endothelial cells by atomic force microscopy. Micron, 2017; 101: 48-53. 